\title{
Seismic observations of sea swell on the floating Ross Ice Shelf, Antarctica
}

\author{
L. M. Cathles IV, ${ }^{1}$ Emile A. Okal, ${ }^{2}$ and Douglas R. MacAyeal ${ }^{1}$ \\ Received 29 October 2007; revised 25 August 2008; accepted 15 January 2009; published 6 May 2009.
}

[1] A seismometer operating on the floating Ross Ice Shelf near its seaward ice front (Nascent Iceberg) for 340 days (out of 730 days) during the 2004, 2005, and 2006 Antarctic field seasons recorded the arrival of 93 distantly sourced ocean swell events displaying frequency dispersion characteristic of surface gravity waves propagating on deep water. Comparison of swell event dispersion with the NOAA Wave Watch III (NWW3) ocean wave model analysis reveals that 83 of these events were linked to specific storms located in the Pacific, Southern, and Indian oceans. Nearly all major storms in the NWW3 analysis of the Pacific Ocean were linked to signals observed at the Nascent site during the period of seismometer operation. Swell-induced motion of the Ross Ice Shelf is found to increase by several orders of magnitude over the time period that sea ice surrounding Antarctica decreases from its maximum extent (October) to its minimum extent (February). The amplitude of vertical vibration of the ice shelf in the frequency band between 0.025 and $0.14 \mathrm{~Hz}$ varies between tens of micrometers to millimeters as sea ice decays to its minimum seasonal extent. This suggests that climate influence on sea ice extent may indirectly modulate swell energy incident on the calving margins of the Antarctic Ice Sheet. The largest swell signals observed on the Ross Ice Shelf come from storms in the tropical Pacific and Gulf of Alaska. These remote events emphasize how the iceberg calving margin of Antarctica is connected to environmental conditions well beyond Antarctica.

Citation: Cathles, L. M., IV, E. A. Okal, and D. R. MacAyeal (2009), Seismic observations of sea swell on the floating Ross Ice Shelf, Antarctica, J. Geophys. Res., 114, F02015, doi:10.1029/2007JF000934.

\section{Introduction}

[2] Three-dimensional motions induced by ocean waves incident on ice shelves, ice tongues and icebergs may be a contributing mechanism for ice fatigue and fracture necessary for iceberg calving, iceberg break-up and ice shelf disintegration. Wadhams et al. [1983, see also Goodman et al., 1980; Kristensen et al., 1982; MacAyeal et al., 2006] have shown that ocean waves produce strong flexural motions of tabular icebergs adrift in the Southern Ocean, and suggest that these motions may eventually contribute to their break-up. Holdsworth and Glynn [1978, see also Squire et al., 1994] have studied vibrational modes of the Erebus Glacier Tongue that floats off the edge of Ross Island, Antarctica, and have suggested that its relatively infrequent calving is associated with times when its natural flexural vibrations are tuned to excitation by ocean swell. Massom et al. [2006] suggest that ocean swell played a role in the disintegration of the Larsen B Ice Shelf in March of 2002. A recent (February and March of 2008) break-up of

\footnotetext{
${ }^{1}$ Department of Geophysical Science, University of Chicago, Chicago, Illinois, USA.

${ }^{2}$ Department of Earth and Planetary Sciences, Northwestern University, Chicago, Illinois, USA.

Copyright 2009 by the American Geophysical Union. 0148-0227/09/2007JF000934\$09.00
}

portions of the Wilkins Ice Shelf (see http://nsidc.org/news/ press/20080325_Wilkins.html) reinforces this suggestion because the February/March timing of both the Larsen B and Wilkins ice shelf disintegrations occurred when sea ice conditions around Antarctica were minimal.

[3] Despite a prominent glaciological role attributed to ocean swell, relatively few measurements of the influence of swell on icebergs and the large Antarctic ice shelves have been performed in the recent past. Kristensen et al. [1982] deployed accelerometers, tilt meters and strain meters on tabular icebergs in the Southern Ocean near the South Shetland Islands to investigate iceberg response to ocean swell. Their research indicated that icebergs can display a resonant response to swell, however their field program was short, and only involved several days of operation. Gravimeters used to study ocean tides on the Ross Ice Shelf [Williams and Robinson, 1981] also detected motions attributed to ocean swell with period below $100 \mathrm{~s}$ at a location about $600 \mathrm{~km}$ south of the seaward ice front where the ice shelf thickness was approximately $500 \mathrm{~m}$. In both prior measurement efforts, the results came at the cost of very great logistical effort, thus making further study less appealing.

[4] In the present study, results of a multiyear field campaign designed to identify seismic and other signals on the Ross Ice Shelf are presented to provide additional insight into the characteristics and role of sea swell incident on the margin of Antarctica's ice sheet [Okal and MacAyeal, 


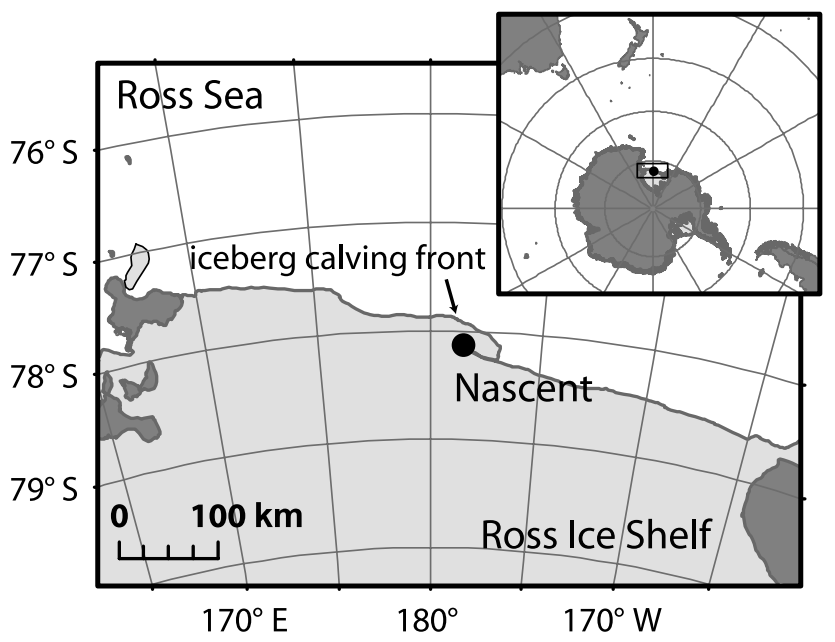

Figure 1. Nascent Iceberg on the seaward ice front of the Ross Ice Shelf (ice front and rift location determined from Moderate Resolution Imaging Spectroradiometer image dated 8 November 2004, see http://nsidc.org/data/iceshelves images/ross_east.html). Seismometer site location denoted by a dot. The rift trending from the southeast toward an actively propagating tip in the northwest (closest to the seismometer site) cuts vertically through the ice shelf from top to bottom and will thus become an iceberg detachment boundary sometime in the coming decades. The seismometer was deployed near the rift in an effort to observe signals associated with iceberg calving.

2006]. The data featured in this study were collected by a seismometer deployed approximately $25 \mathrm{~km}$ south of the seaward calving front of the Ross Ice Shelf near a large rift expected to eventually produce a new tabular iceberg in the coming decades. (This rift was also part of the detachment boundary producing iceberg B15 in March 2000 [Lazzara et al., 1999].) This ice shelf site $\left(78^{\circ} 7.5^{\prime} \mathrm{S}, 178^{\circ} 32.0^{\prime} \mathrm{W}\right)$, shown in Figure 1, is called Nascent Iceberg in reference to the expectation that the site will eventually become part of a large $30 \mathrm{~km}$ by $50 \mathrm{~km}$ tabular iceberg sometime in the coming decade. Ice thickness at the Nascent Iceberg site is approximately $250 \mathrm{~m}$ [Bentley et al., 1979], and water column thickness (between the underside of the ice shelf and the sea bed) is approximately $400 \mathrm{~m}$ [Davey, 2004].

[5] This paper summarizes the characteristics of distantly sourced sea swell incident on the Ross Ice Shelf recorded by our seismometer. The summary is based on a catalogue of 93 sea swell arrival events detected during a total of 340 days (out of 740 days) when the seismometer's photovoltaic power system was operating. The periods of operation cover the periods of 2 years when sea ice in the ocean surrounding Antarctica changed from maximum extent (early October) to minimum extent (late February). Our data thus provides an assessment of the moderating influence of sea ice on sea swell arriving from distant ocean sources beyond Antarctica. Each of the arrival events in our catalogue were characterized by the dispersion properties of surface gravity waves traveling on deep water (i.e., the dominant frequency of the swell signal associated with each event arriving at the station increased slowly with time). This dispersion allowed the distance to the source, or focus of swell origin, to be estimated, and the events to be tied to specific storms recorded in global environmental data.

[6] The results of the analysis provide a descriptive sea swell phenomenology for the Ross Ice Shelf and further documents the previously known fact that sea swell propagation is a transoceanic phenomenon [Munk et al., 1963; MacAyeal et al., 2006] that links the margins of the Antarctic Ice Sheet to environmental conditions, particularly storminess, around the globe. Because our study encompasses the analysis of only a single seismometer record at a single location, our analysis does not include an effort to characterize the process that converts sea swell incident on the Ross Ice Shelf into motions of the ice shelf (e.g., whether the ice shelf motions are responding to local swell propagation or to some integral effect of swell distributed across a region of the ice shelf). We also restrict our analysis to the most basic implications of the sea swell catalogue, and thereby take oceanographic and meteorological analysis of global storminess at face value when estimating the likely source of events in the catalogue. These restrictions will be relaxed in future study when greater spatial coverage (more seismic stations) is available on the ice shelf.

\section{Summary of Ice Shelf Seismometer Signals}

[7] The seismometer recorded a variety of signals during the field campaign [Okal and MacAyeal, 2006] including earthquakes, tsunamis, iceberg-generated tremor and, what is featured in the present study, sea swell incident on the ice shelf from points of origin distributed across the North and South Pacific, the Indian and the Southern oceans. In this respect, a unique aspect of this deployment is that the seismometer on the floating ice shelf responds not only to elastic waves propagating in the ice, but directly to the motion of the ice shelf as a whole, even if the ice is totally rigid (e.g., as when the ice shelf rocks and bobs, as described by Okal and MacAyeal, 2006), as well as to flexure of the ice shelf as it attempts to conform to the ocean surface on which it floats (e.g., as is the case of flexural gravity waves described by Williams and Robinson, 1981). Indeed, Okal and MacAyeal [2006] showed that this seismometer (and similar ones located on nearby drifting icebergs) recorded the 3-D motion of the surface of the sea during the great 2004 Sumatra tsunami. This establishes that seismometers on floating ice do function as sensors of the vertical displacement of the surface of the ocean, and therefore operate in a sense as buoys, contrary to their counterparts deployed on a continent or island, that only record elastic vibrations resulting from the conversion of the oceanic wave at the fluid/solid interface [Bromirski and Duennebier, 2002] that, for example, can induce significant nonlinearities such as the classically known doubling of frequency in microseisms [e.g., Okal and MacAyeal, 2006, Figure 9]. For the purposes of our study, we assume that the ice shelf motions recorded at Nascent Iceberg describe the state of sea swell in the ice-free ocean in a region relatively close to the seismometer deployment site. Dispersion effects associated with conversion of swell in the ice-free ocean to rigid body rocking and bobbing of the ice shelf, or to the elastic flexure motions associated with flexural gravity 


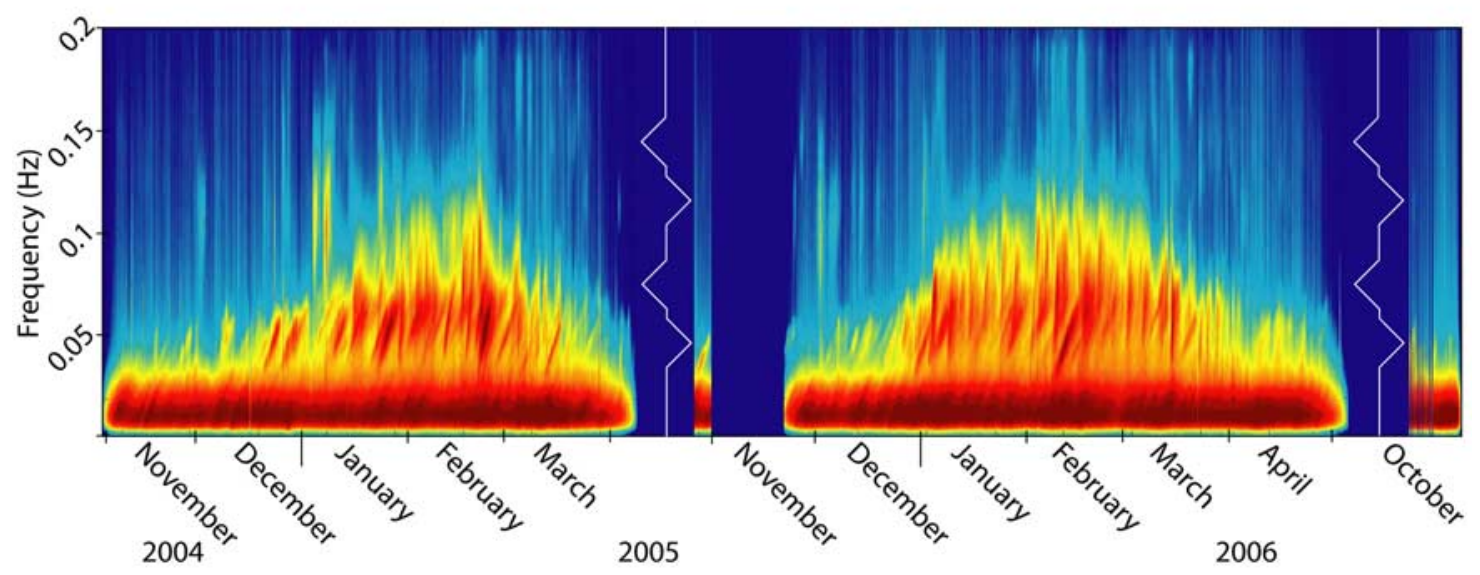

Figure 2. A 2-year spectrogram of vertical displacement constructed from the seismometer record at Nascent Iceberg. Color indicates the $\log _{10}$ of signal density as a function of time (horizontal axis) and frequency (vertical axis) expressed in units of $\mathrm{dB}$ of $\mathrm{cm}^{2} \mathrm{~s}^{2} \mathrm{~Hz}^{-1}$; red is higher density and blue is lower density with the range between red and blue being $3 \mathrm{~dB}$. Two major features are displayed by the spectrogram. First, the intensity of signal in the $0.025-0.15 \mathrm{~Hz}$ range increases dramatically as the sea ice conditions in the Ross Sea and beyond become less concentrated and extensive [Gloerson et al., 1992]. Maximum signal intensity occurs in the late February to early March time periods, when sea ice concentration and extent is minimum. Minimum intensity occurs in the late October time periods, when sea ice concentration and extent is maximum. Second, the sequence of ocean swell arrival events signifying teleconnection with swell-producing storms distant from Antarctica. The high-intensity (red/ orange color) diagonal swaths seen in the record (tilting from lower left toward upper right), particularly from early January to end of March during both years of deployment (2005 and 2006) are sea swell arrival events characterized by frequency-dispersed wave trains. Ninety-three such swell events are identified in the seismometer record, 83 were identified with specific swell-producing storms through comparison with NOAA Wave Watch III wave model analysis.

waves [Williams and Robinson, 1981], are disregarded in this study, because we assume that the short distances traveled from the conversion site to the seismometer disperse the swell much less than effects in play during the swell's transit across the ice-free ocean.

[8] A summary of signals recorded by the seismometer during the $\sim 340$ days of operation over the 2004-2006 field seasons is shown in Figure 2. This spectrogram displays vertical seismic displacement energy density as a function of frequency and time (a complete description of the spectrogram's construction is provided below). Signals with timescale shorter than a few days are not well displayed in this spectrogram, because its intent is to display the most prominent characteristics of seasonality in the signal. Signal energy density in the $0.025 \mathrm{~Hz}$ to $0.15 \mathrm{~Hz}$ range conspicuously increases during the months (early December to late April) when sea ice around Antarctica retreats during the Austral summer. Signal energy in the $0.025 \mathrm{~Hz}$ to $0.15 \mathrm{~Hz}$ range amplifies as sea ice conditions both in the Ross Sea and in the greater Southern Ocean surrounding Antarctica decay in early December. Signal energy is highest in amplitude during the February and early March period of minimum sea ice extent, and reduce to a minimum in late April when sea ice again returns to the Ross Sea and the Southern Ocean. It is notable that the break-up of ice shelves along the Antarctic peninsula (e.g., the Larsen B Ice Shelf, which broke up in 2002 [Scambos et al., 2003] and the Wilkins Ice Shelf [Braun and Humbert,
2009; Braun et al., 2008] which suffered two episodes of partial break-up in 2008) tend to break up at times when our seismometer data suggests that vibrations in the $0.025 \mathrm{~Hz}$ to $0.15 \mathrm{~Hz}$ range are greatest. The extent to which signal energy is suppressed during the Austral winter season when sea ice coverage is extensive in the Ross Sea and Southern Ocean is unknown, because our instruments depended on photovoltaic power to operate.

[9] Ocean swell signals in the spectrogram data of Figure 2 are identified by swaths of high signal energy density (red color) that tilt from lower left to upper right (indicating dispersion). Our objective in the present study is to deduce from these signals the degree to which the Ross Ice Shelf experiences the effects of distant storms. It is important to note that our focus is on swell signals that propagate in deep ocean over distances $>340 \mathrm{~km}$. Signals from distant storms are more easily identified than signals from nearby storms because of the characteristic frequency dispersion associated with waves on deep water [Munk et al., 1963]. Swell generated by storms close to the Ross Ice Shelf, e.g., $<350 \mathrm{~km}$ from the seismometer site, during times when sea ice conditions are minimal (e.g., including when polynyas develop in the Ross Sea) are difficult to differentiate as specific events, and are here relegated to being "background noise" (i.e., excluded from our catalogue) that is lumped together with other forms of local meteorological forcing that cause the ice shelf to bob, pitch and roll [Okal and MacAyeal, 2006]. The swell arrival event displaying the 
least dispersion in our data, but that was still identifiable from background noise, was located at the edge of the Ross Sea, approximately $380 \mathrm{~km}$ from the seismometer site.

\section{Field Methods and Data Analysis}

[10] A Guralp 40 $\mathrm{T}^{\mathrm{TM}}$ seismometer on loan from the IRIS/ PASSCAL instrumentation program was deployed on 4 November 2004, in a firn pit, approximately 1.5 meters in depth, located about $1 \mathrm{~km}$ North of a large rift on the Ross Ice Shelf (Figure 1). The seismometer was oriented and leveled on a ceramic tile that was firmly placed on a smooth, level surface of the snow pit floor. The threechannel signal from the seismometer was digitized at $100 \mathrm{~Hz}$ and at $1 \mathrm{~Hz}$ by a Quanterra Q330 ${ }^{\mathrm{TM}}$, and was recorded on a Quanterra Baler ${ }^{\mathrm{TM}}$ furnished with 9 Gbytes of flash memory necessary to withstand sub freezing temperature. (See http:// www.passcal.nmt.edu/ for instrument details.) Photovoltaic charging was used to power the system, and this restricted data collection to the 340 days of the 2-year instrument deployment when the sun was above the horizon. The instrument operated during the mid October to early April time periods of 2004-2005 and 2005-2006. Data were harvested from the field site twice, once during a servicing visit to the station in November 2005 and a second time at the end of the measurement campaign, when the instrument was withdrawn from the field in late October 2006. Once collected, data were processed to convert seismometer signals to seismic velocity and displacement using standard deconvolution techniques to remove instrument response characteristics (e.g., following methods described in section 4.3.1 of Stein and Wysession [2003]). The seismometer (Guralp 40T ${ }^{\mathrm{TM}}$ ) has a flat frequency response to ground velocity above $0.1 \mathrm{~Hz}$, and the natural frequency of the instrument is $1 / 30 \mathrm{~Hz}$. Signal strength at frequencies below approximately $1 / 30 \mathrm{~Hz}$ decay because of this instrument response, and this precludes analysis of signals at periods above $\sim 100 \mathrm{~s}$.

[11] Our study made extensive use of spectrograms created from $1 \mathrm{~Hz}$ sampled data such as that shown in Figure 2 which covers the complete 340-day record of Nascent Iceberg vertical displacement in the frequency range from 0 to $0.2 \mathrm{~Hz}$. Spectrograms shown here, and those used in the context of other data analysis tasks not explicitly shown, were created using Matlab ${ }^{\mathrm{TM}}$ Oppenheim and Schafer [1989], see also, http://www.mathworks.com for a description of the $[\mathrm{S}, \mathrm{F}, \mathrm{T}]=\operatorname{spectrogram}(\mathrm{x}$, window,noverlap, $\mathrm{F}, \mathrm{fs})$ routine; the Matlab ${ }^{\mathrm{TM}}$ spectrogram methodology involves user-chosen parameters that influence the visual display: the size of the Hamming data-sampling window, and the number of overlapping window segments; these parameters were set to 1000 and 500, respectively, for Figures 5 and 6 and 1500 and 750 for Figure 2). The principal function of the spectrograms we constructed in our analysis was to detect the arrivals of sea swell. These arrivals are featured as swaths of large (relative to background noise) seismic displacement signal density (displayed as $d B$ of $\mathrm{m}^{2} \mathrm{~s}^{2}$ $\mathrm{Hz}^{-1}$ ) with a characteristic frequency versus time of arrival slope $(d f / d t$ where $f$ is frequency in $\mathrm{Hz}$ and $t$ is time of observation). Determination of this slope constituted the only quantitative element derived from spectrograms con- structed in our study, as it is a parameter that describes wave train frequency dispersion that determines source-to-receiver great circle distance. Other aspects of the spectrograms used in this study are simply used to provide qualitative information about wave train signals compared to other signals recorded by the seismometers, e.g., to show that swell arrival events are easily distinguished from each other, and that sea ice surrounding Antarctica appears to influence the level of background noise. To improve the clarity of Figures 2, 5, and 6, spectrogram images are smoothed using an 8 by 8 pixel subimage running average. Unsmoothed spectrograms were used for all analysis of dispersion used to estimate distance to sea swell origin.

[12] Analysis of our data focussed primarily on the determination of receiver-to-source distance and time of origin of distinct swell arrival events observed in our 340-day seismometer record. This analysis was performed by examination of the linear swaths of high signal intensity appearing in spectrograms constructed from the seismic displacement recorded by our instruments. These spectrograms, typically showing shorter (e.g., less than 15 days) segments of the full time series spectrogram shown in Figure 2, were analyzed to compute frequency versus time-of-arrival slope $(d f / d t)$ that indicate a representative distance to the focus of swell origin [Munk et al., 1963]. Swell origin is a process that involves air/sea interaction spread over significant time and space. Remarkably, the swell arrival events at Nascent often have tightly constrained $d f / d t$ values suggesting swell origin that is more tightly constrained in time and space than expected from typical storm conditions (e.g., storms last a number of days and move over significant distances). In recognition of synoptic storm variability, we refer to the swell origin location and time determined from $d f / d t$ as the "focus" of swell origin.

[13] Distance and wave traveltime from focus to observer is determined following the methods described by Munk et al. [1963]. Using the dispersion relation for waves traveling on deep water, i.e., where wavelength is much less than water depth, the distance to focus $x$ of waves arriving at a particular observation site may be written

$$
x=\frac{g}{4 \pi}\left[\frac{d f}{d t}\right]^{-1}
$$

where $d f / d t$ is the rate of change of frequency $f(\mathrm{~Hz})$ with time $t$ observed for arriving waves, and $g=9.81 \mathrm{~m} \mathrm{~s}^{-2}$ is the acceleration of gravity. The total time in transit $\Delta t(\tilde{f})$ of waves at frequency $\widetilde{f}$ required to travel the distance $x$ is given by

$$
\Delta t=\frac{4 \pi \tilde{f}}{g} x .
$$

Figure 3 summarizes the geometry of arrival events depicted in frequency versus time spectrograms of arriving sea swell.

[14] To estimate $x$ and the time of swell origin, $t_{o}$, for a particular swell arrival event in our data, a short sample of the seismometer record was extracted to provide a 4 day to 

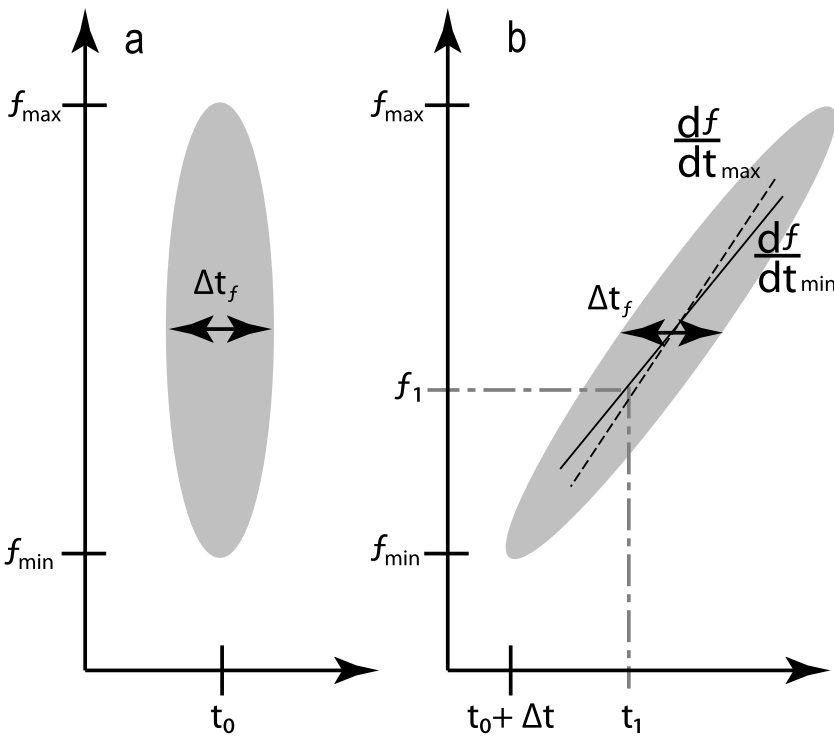

Figure 3. Evolution of an idealized wave packet as it would appear in a spectrogram. Shaded regions denote the area occupied by the wave packet in frequency/time space. (a) Initial distribution of wave energy across a frequency and time range. (b) Distortion of the area in frequency/time space occupied by the wave packet after a time $\Delta t$ due to wave dispersion. When in deep water, high-frequency waves travel more slowly than low-frequency waves, so the distribution of wave energy (gray ellipse) tilts to the upper right as the time $(\Delta t)$ and distance between the point of observation and origin is increased. To determine the focus of swell origin for events in our data, the slope of the energy distribution, $d f / d t$, associated with each sea swell arrival event was measured on spectrograms of the seismometer signal. Uncertainty of $d f / d t$ associated with the measurement algorithm (above, and in the algorithm), denoted by estimates of $d f /\left.d t\right|_{\max }$ and $d f /\left.d t\right|_{\min }$, is used to estimate the uncertainty of distance to the focus.

8 day time interval containing the event (typical dispersion of one event would produce an arrival recorded at Nascent iceberg that would last between less than 1 day to about 8 days). A spectrogram of this sub record was constructed, and the slope $d f / d t$ was extracted by fitting a line to the swath of high-energy density using a graphical technique. All fits were quality checked by visual inspection to ensure that events were not spuriously created from noisy record sections and to ensure that events were not missed. To aid the identification of $d f / d t$ for individual events, an automatic algorithm was used, to be described below, however, we emphasize that the detection of events was controlled by visual inspection of spectrograms.

[15] The algorithm which aided the effort to measure the $d f / d t$ for events identified visually on spectrograms of the short subrecords is described as follows. First, a rhomboidal region in the $(t, f)$ plane represented by the spectrogram, $S(t, f)$, containing the linear swath of high signal strength was manually selected to visually isolate the subregion of the spectrogram containing one distinct event. This was done by selecting $4(t, f)$ points on the spectrogram that outline the swath of high-energy density associated with a single arrival. Second, identification of $(t, f)$ points within this rhomboidal region where $S(t, f)$ exceeded $90 \%$ of its maximum within the rhomboidal region, i.e., points $(t, f)$ where $S(t, f) \geq 0.9 \max S$, were identified. A further selection was made to reduce the number of points identified in the second step by identifying only the two with largest $S(t, f)$ for each time $t$ sampled. In cases where the maximum intensity at a given time occurred at more than two frequencies, the point with the highest frequency was selected so as to emphasize the leading edge of the arriving swell in the $(t, f)$ plane. Third, a least-squares regression was used to fit a line to the selected $(t, f)$ points satisfying the above criteria, and $d f / d t$ was determined from this line. The slope $d f / d t$ so derived was used in equation (1) to determine $x$.

[16] The determination of $t_{o}$, the time of swell origin, was determined by subtracting $\Delta t$ computed for an arbitrary frequency $\tilde{f}$ on the leading edge of the swell arrival event (i.e., where $\tilde{f}$ is the $f$ value of an arbitrary point on the leastsquares line that determines $d f / d t)$ from the time $t(\tilde{f})$ where that arbitrary frequency was observed arriving in the data. This gives $t_{o}=t(\tilde{f})-\Delta t(\tilde{f})$. For both $x$ and $t_{o}, 95 \%$ confidence intervals were computed from the above leastsquares regression used to estimate $d f / d t$. Typical levels of $95 \%$ for swell arrival events observed were $\sim 500 \mathrm{~km}$ and $\sim 1$ day.

\section{Microseism, Meteorology, and Floating Ice Shelves}

[17] It has long been known that seismometers routinely record vibrations (generally called "microseisms") of meteorological/oceanographic origin, which have often been regarded as a nuisance by observational seismologists interested in earthquake phenomena, since microseisms contribute significantly to background noise, most prominently in the $3 \mathrm{~s}$ to $7 \mathrm{~s}$ period range. In this respect, the study of microseisms goes back to the early days of seismology and has involved such eminent researchers as Emil Wiechert, Beno Gutenberg (who wrote his Ph.D. dissertation in Göttingen on this subject), Kiyoo Wadati, James Macelwane, and Frank Press, to name a few [Wiechert, 1904; Gutenberg, 1912; Wadati and Masuda, 1935; Macelwane, 1946; Press and Ewing, 1948]. It was soon realized that microseisms consist mainly of Rayleigh waves (with overtones) propagating in the shallowest part of the crust of islands and continents, and are generated at their coastlines upon conversion to an elastic form of the gravitational energy carried by storm waves propagating over deep oceanic basins. The latter are themselves generated by major storm systems, including tropical depressions regionally known as hurricanes, typhoons or cyclones.

[18] As early as 100 years ago, this motivated investigators to try to "invert" microseismic records into some descriptive property (mainly location, but conceivably also strength) of their meteorological source. Linke [1909] correlated characteristic properties of microseismic waves to storm patterns off Samoa. Later, Gilmore [1946], working under Macelwane's supervision, laid the foundation of an early hurricane detection system for the Caribbean [Gutenberg, 1947], obviously rendered obsolete by the advent of space 
imagery in the ensuing decades. The study of microseism as a tool in the investigation of oceanic storm systems and sea swell nevertheless remains vibrant [e.g., Bromirski and Duennebier, 2002; Aster et al., 2008], and has involved detailed analyses of the complex transfer function between fluid and solid displacements, which can take a nonlinear, potentially catastrophic dimension upon breaking at the shoreline, as illustrated dramatically in our preliminary study [Okal and MacAyeal, 2006, Figure 9]. Our methodology avoids such problems because the ice shelf fragment hosting the station is to a large extent entrained by the water wave, of which the instrument provides a direct record.

\subsection{Comparison With NOAA Wave Watch III Model Analysis}

[19] We calculate the distance to the origin of the waves, and then estimate the location within the annulus by assuming the most likely origin of the long-period swell is colocated with the highest amplitude mean significant wave height, which reports the wave height of short-period waves modeled in NOAA Wave Watch III (WW3) model. We have observed that in correlating the most likely origin within the annulus, that we do not 'see' any storms with a mean significant wave height of less then 5 meters. This does not mean that the waves which we observe (the longperiod swell) have peak to trough heights of 10 meters. We are merely suggesting that the event which generates mean significant wave heights of 5 meters transmits enough power to the ocean that the long-period swell which it also generates can propagate significant distances.

[20] Following the compilation of the swell arrival catalogue, we investigated whether the events of the catalogue correspond to storms apparent in common meteorological and oceanographic observations and data analysis products. We compared the estimates of distance-to-origin, $x$, and time-of-origin, $t_{o}$, derived from the dispersion characteristics of swell events in the catalogue with a widely accepted ocean-wave state data analysis product produced by the NWW3 model. We make no attempt to justify the integrity of the NWW3 analysis product, and simply accept its description of global surface wave conditions at face value. The NWW3 (version 2.22) model analysis product is described by Tolman [2002] (more information is available online at http://polar.ncep.noaa.gov/waves/wavewatch/; data are available via anonymous FTP at ftp://polar.ncep.noaa. gov/pub/history/waves/). We observe that the NWW3 product does not analyze the frequency range that dominates the swell signal on the Ross Ice Shelf, however we assume that any significant swell source identified in the NWW3 will generate high-energy swell at all frequencies, including those lower than the lowest wave frequency treated in the NWW3 analysis.

[21] For each event in the catalogue, the $95 \%$ confidence interval of distance-to-origin, $x$, maps to an annular strip on the earth's surface bound by two small circles, with their pole at the observation site (e.g., as shown as white and black lines in Figure $5 \mathrm{~b}$. The $95 \%$ confidence interval of $t_{o}$, for each event, defines a time span of approximately 1 day. These confidence limits defined a search region in space and time where the NWW3 analysis was inspected to locate a possible source of swell. The NWW3 model output parameters most useful for identifying a possible source are (1) the significant wave height (i.e., we looked for localized regions having high wave amplitudes, e.g., greater than $5 \mathrm{~m}$, within the search region) and (2) peak wave direction (i.e., we required that the localized regions of significant wave height have wave propagation directions directed toward the Ross Sea). In several cases where the localized region of wave generation in the NWW3 analysis had a wave height of less then $50 \%$ of the maximum significant wave height within the annular strip, we relax the requirement that the peak wave direction be directed toward the Ross Sea. Figure 4 shows the distribution of estimated swell origin foci determined by comparing the $x$ and $t_{o}$ estimates from our catalogue with the NWW3 analysis product.

[22] Once a focus for a given swell arrival event was located, a check was made to determine whether a clear, unobstructed great circle path exists between the focus and the seismometer receiver site at Nascent Iceberg. In 63 of 83 cases, unobstructed great circle paths existed (signified by blue or red colored symbols in Figure 4). For 20 cases (signified by gray filled symbols in Figure 4), the great circle path was obstructed by the continental land mass of Antarctica. The zone of unobstructed great circle path from storms in the Pacific and Southern oceans is designated by two great circles in Figure 4 denoted by heavy dashed (connecting Nascent to Cape Adare) and dashed-dotted (connecting Nascent to Edward VII Peninsula) lines.

[23] Examples of consistency between NWW3 and the results of our seismically determined foci of swell origin are shown in Figures 5 and 6. In Figure 5, we illustrate two wave trains arriving at the Nascent Iceberg site on 26 February and 2 March 2005. The annular confidence limit region for the 26 February arrival determined by the dark lines on the spectrogram (Figure 5a) is shown by the two dark circles superimposed on the map of significant wave height predicted by the NWW3 model for 18 February 2005 the day corresponding to $t_{o}$. A local maximum of significant wave height in the NWW3 analysis located in the western Gulf of Alaska falls within this annular region, and is identified as the most likely source of swell observed at Nascent Iceberg 9 days later. This NWW3 source is denoted by a star in Figure 5b. Both the wave height (above $9 \mathrm{~m}$ ) and direction of principal propagation $\left( \pm 22.5^{\circ}\right.$ of the azimuth from the storm origin to the observation site) for this 18 February 2005 event were favorable for generating waves that would propagate across the Pacific to the Ross Sea.

[24] A second wave train arriving on 2 March 2005 shown in Figure 5a, is puzzling, because the spatial extent of the search region implied by the $95 \%$ confidence limit on distance-to-origin, $x$, associated with the event falls beyond the coastal boundaries of the Pacific Ocean. This is an example of 10 events in the 93-event catalogue where correspondence with a likely source in the NWW3 analysis product could not be found. We relegate to future work the effort to determine the cause of these disagreements.

[25] The NWW3 analysis predicts wave frequency dispersion along the direction of swell propagation. Dispersion of swell emanating from two storms in the North Pacific as predicted by the NWW3 model are shown in Figure 6. Swell from these two storms, labeled I and II in Figures $6 \mathrm{~b}-6 \mathrm{~g}$, is depicted in flight over an 11-day period in December 2004. Swell event I is sourced in the Gulf of Alaska on 


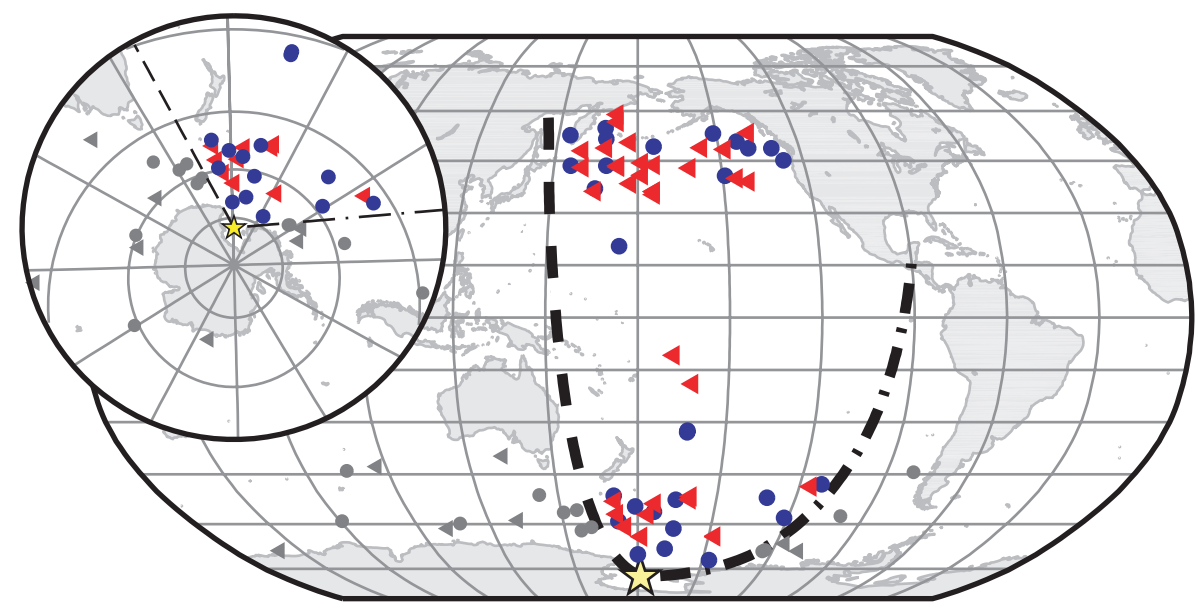

Figure 4. Foci of swell origin for observed sea swell arrival events at Nascent Iceberg (denoted by gold star in the Ross Sea, Antarctica) determined from comparison of seismic data and the NWW3 analysis (main map, Robinson projection; small map, gnomonic projection). Swell origin foci are generally within the Northern and Southern Hemisphere extratropical storm tracks, however, two foci are associated with tropical typhoons. Triangles denote foci associated with the November-May period of 2004-2005. Circles denote foci associated with the October-May period of 2005-2006. Two dark dashed lines emanating from Nascent Iceberg (gold star) are great circles denoting limits unobstructed view where storms in the Pacific and Southern oceans have direct, unobstructed great circle paths to the seismometer observation site. Foci located within this realm are colored blue or red (depending on time period of observation denoted by symbol). The western limit is determined by the great circle connecting Nascent to Cape Adare, Antarctica. The eastern limit is determined by the great circle connecting Edward VII Peninsula to Nascent Iceberg. Foci located in parts of the Pacific, Indian, and Southern oceans which have obstructed great circle paths to the seismometer site are indicated in gray. Diffraction may account for the observation of swell generated by sources that are shadowed by land masses, however, we do not rigorously test this suggestion.

18 December 2004, where the significant wave height exceeded $\sim 12 \mathrm{~m}$ (Figure 6a). Swell event II is sourced at a similar location from a storm occurring several days earlier in time. As the swell propagates to the southeast, nearly filling the entire Pacific basin, waves with periods exceeding $\sim 16 \mathrm{~s}$ advance in front of slower-moving waves with shorter periods. This dispersion is signified in Figures $6 \mathrm{~b}-6 \mathrm{f}$ by the yellow-to-red color gradient in the direction of propagation (indicated by black arrows in Figures $6 b-6 f$ ). As the swell wavetrain advances into the southern Pacific, the distance between the leading edge (signified by red color indicating long-period swell) and the trailing edge (indicated by yellow color) increases, and this translates to temporal dispersion at receiver sites of the nature shown in Figure 3. In the spectrogram of signals at Nascent (Figure 6g), the arrivals of swell events I and II are displayed (swell event I on 26 December 2004 and swell event II on 20 December 2004). The $d f / d t$ slope of these arrival events on the spectrogram is consistent with what NWW3 model analysis predicts for points at the extreme southern boundary of the NWW3 analysis grid (just north of the Nascent seismometer site). This consistency with the NWW3 analysis places additional confidence on the interpretation of swell arrival signals at Nascent.

\subsection{Sea Swell Arrival Event Catalogue}

[26] In the full, 2-year record at Nascent Iceberg, 93 sea swell arrival events were identified. Of the 93 events, 83 were confidently associated with storms distributed across the Indian, Pacific and Southern oceans. The foci of swell origin for 10 of the 93 arrival events failed to be identified by comparison with the NWW3 analysis described in the previous section. Figure 4 shows the locations of storms that were confidently associated with swell arrival at Nascent Iceberg. These locations are evenly distributed between the Northern and Southern hemispheres (Figure 7), and do not appear to show bias between the eastern or western Pacific Basins. The Ross Ice Shelf is observed to receive varying amounts of swell from distant storms. The impact of storm activity during May through September is unclear because of sampling bias toward the period when photovoltaic power to the seismometer was operational, and this may also contribute, along with sea-ice seasonality, to why the maximum number of events occurs in the Austral summer (Figure 7c). The significant wave height varies greatly as does the duration of seismic events. The bell-shaped distribution of event duration (Figure 7a) is perhaps most surprising given the strongly bimodal distribution of swell propagation distance (Figure $7 \mathrm{~b}$ ), and suggests a large variability in length of storms which produce swell which eventually is observed at distant locations. Further analysis of the NWW3 analysis showed that storms must have a significant wave height that exceeds $5 \mathrm{~m}$ (at the frequency where significant waves are defined in the NWW3 product) if they are to produce detectable low-frequency swell at Nascent Iceberg (Figure 7d). 

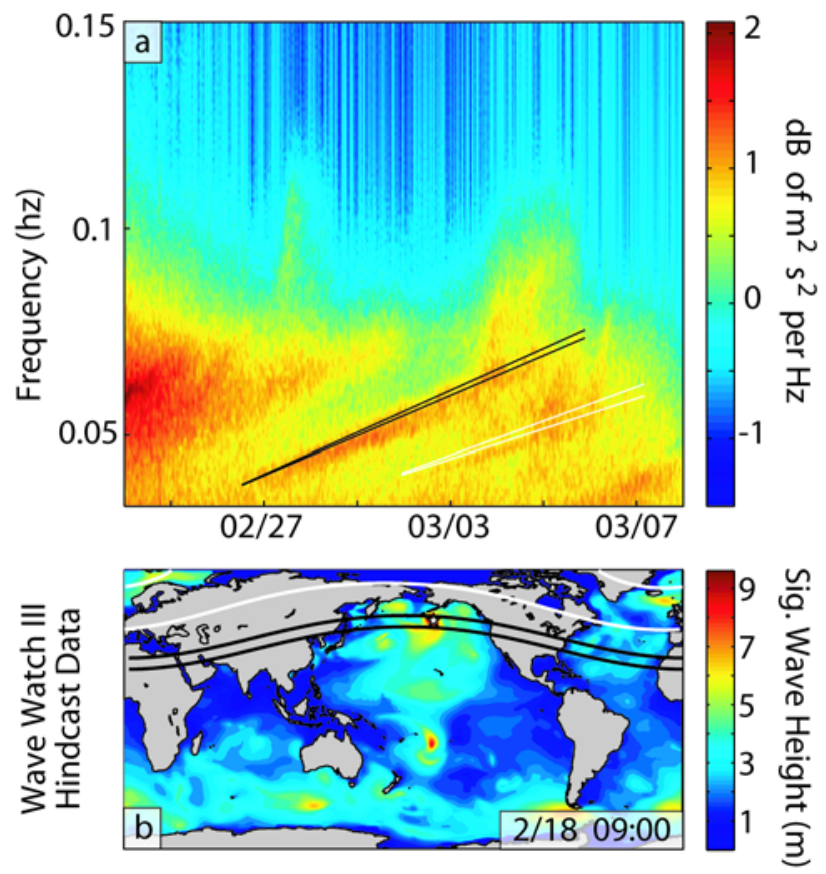

Figure 5. Comparison of seismic data and NWW3 wave model analysis. (a) Spectrogram of the vertical channel of the seismometer signal at Nascent Iceberg during the time period when waves from an 18 February 2005 storm in the Gulf of Alaska arrived at the observation site. Dark lines superimposed on the spectrogram denote the arrival on 26 February 2005 of swell assumed to propagate directly from a Gulf of Alaska source suggested by NWW3 to the Ross Sea. White lines superimposed on the spectrogram denote the arrival on 2 March 2005 of swell that our analysis suggests would have also originated on 18 February 2005 but which has a paradoxical focus of swell origin located beyond the bounds of the Pacific Ocean. (b) Significant wave height (m) from the NWW3 model analysis. The loci of points equidistant from the observation site on Nascent Iceberg with a radius determined by the dispersion of the direct arrival falls across a storm center in the Gulf of Alaska predicted by the NWW3 analysis for 18 February 2005 the time of the sea swell origin.

\subsection{Swell-Induced Ice Shelf Motion}

[27] To illustrate the general magnitude of wave-induced motion of the Ross Ice Shelf near its calving front, vertical displacements were determined from the seismometer data (correcting for instrument response). This vertical motion when swell arrival events were not underway provides a measure of background noise to which motion induced by swell arrival is compared. This background motion consists of bobbing and rocking of the ice shelf associated with buoyancy oscillations [Okal and MacAyeal, 2006] and with flexural motions associated with local meteorological events near the ice front (e.g., swell arriving from storms $<100 \mathrm{~km}$ from the ice front that is not associated with a single focus of swell origin). The average amplitude of displacement integrated over all frequencies during time periods when sea swell arrival events were not in progress was $0.02 \mathrm{~cm}$. The average amplitude of displacement within the typical fre- quency range of observed sea swell (determined to be 0.042 to $0.072 \mathrm{~Hz}$ from our data) was $0.0003 \mathrm{~cm}$ (3 microns). Again, this result applies to time periods when swell arrival events were not underway. The average of the frequency range used in this displacement analysis was determined to be $0.042 \mathrm{~Hz}$ to $0.072 \mathrm{~Hz}$.

[28] In comparison to the background noise, the average amplitude of vertical displacements during periods of time when swell arrival events were underway, averaged over all frequencies, was $0.023 \mathrm{~cm}$. This number is in itself very similar to background noise (see above), but the average of swell-induced displacements in the frequency band of typical swell events was $0.004 \mathrm{~cm}$, giving a signal to noise ratio of about 13 . While the measured displacement integrated over all frequencies seems to be unaffected by the arrival of dispersed waves, there is an order of magnitude increase in induced motion at frequencies of observed dispersive gravity waves. Since energy scales with the square of the displacement, there is a hundredfold increase in energy in the sea swell frequency band during the onset of a swell arrival event. The maximum displacement observed during the strongest swell arrival period was $0.28 \mathrm{~cm}$, an order of magnitude greater than the background noise $(0.02 \mathrm{~cm})$. This indicates that swell from extraordinary sources (in this case, category 5 Typhoon Olaf, Cook-Austral Islands, 14-19 February 2005, see http://en.wikipedia.org/ wiki/Cyclone_Olaf) is identified with the most energetic motion of the ice shelf.

[29] The average frequency of all observed swell events is $0.057 \mathrm{~Hz}$, and the average frequency range identified with swell arrival is $0.042 \mathrm{~Hz}$ to $0.072 \mathrm{~Hz}$. Figure 8 depicts the apparent average 3-D motion induced by swell at the average frequency observed $(0.055 \mathrm{~Hz})$ during the arrival of swell from Typhoon Olaf (Cook-Austral Islands, 1419 February 2005). To obtain the average, apparent 3-D displacements of the seismometer were averaged over a time period equivalent to 100 cycles of the $0.055 \mathrm{~Hz}$ incoming swell. We refer to the motion as apparent because our imprecise understanding of how the ice shelf deforms in response to the sea surface (i.e., flexing to conform to a sunusoidal sea surface undulation versus rigid body rocking set up by the net effect of the waves on the local ice shelf region) prevents us from distinguishing horizontal accelerations due to ground (ice surface) movement from tilt of the ice surface. Given the apparent retrograde nature of the circular motions (i.e., where apparent horizontal motion is toward the presumed wave source at the top of the vertical displacement), it is likely that ice surface tilt contributes strongly to the apparent horizontal motion. The average apparent horizontal and vertical motions are of the same order and that this holds true for the average frequencies of all events (Figures $8 \mathrm{~b}$ and $8 \mathrm{c}$ ).

[30] The energy flux, integrated vertically over the water column depth, associated with surface gravity waves at a single frequency traveling on deep water is given by:

$$
F=\frac{\rho_{w} g a^{2} g}{4 \omega},
$$

where $\rho_{w}$ is $1030 \mathrm{~kg} \mathrm{~m}^{-3}$ is the density of sea water, $a$ is the amplitude of sea surface displacement (vertical displacement on the ice shelf) and $\omega=2 \pi f$ is the angular frequency 

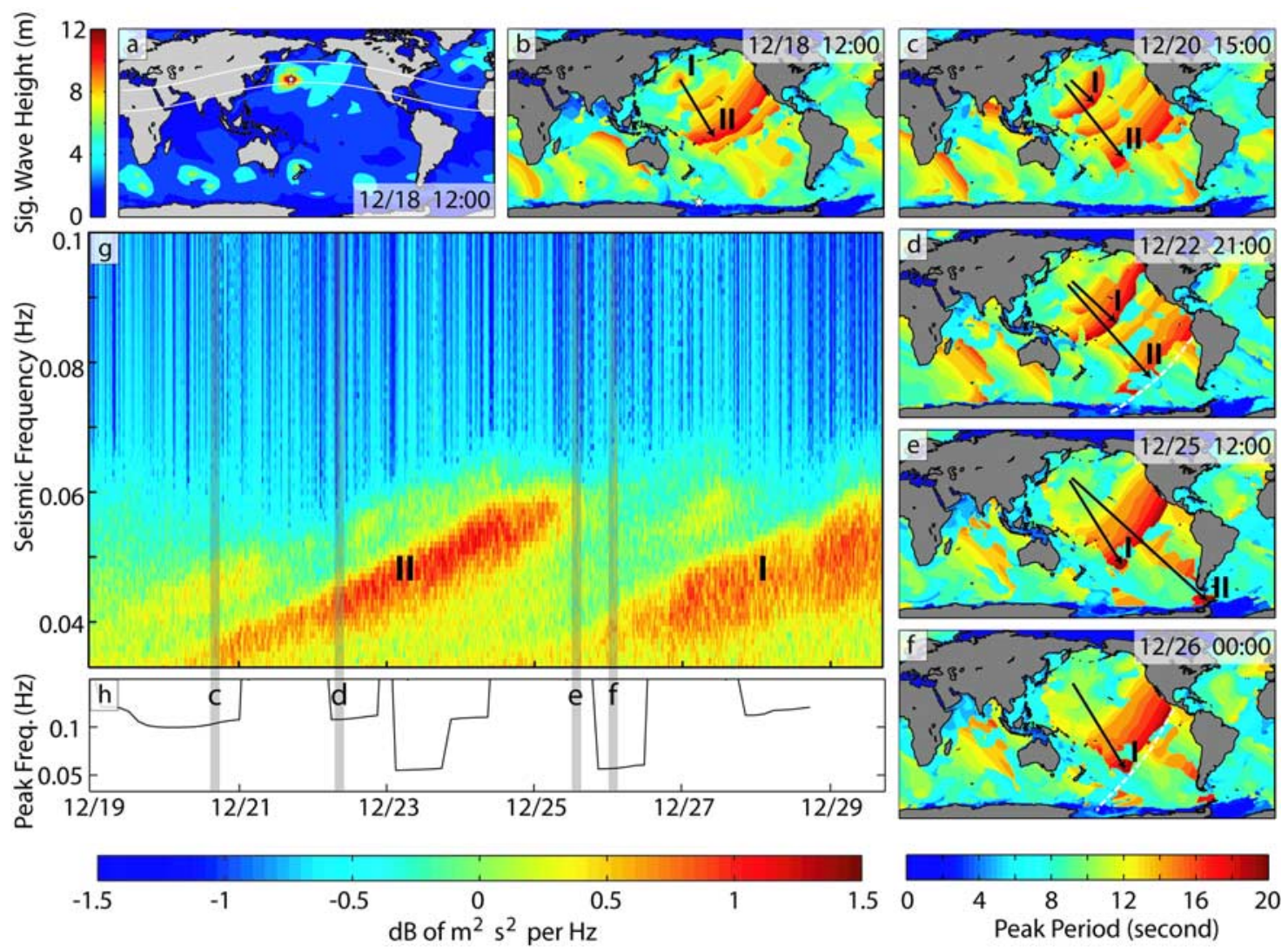

Figure 6. Analysis of wave dispersion associated with transoceanic propagation. (a) Significant wave height from NWW3 for an 18 December 2005 storm in the Gulf of Alaska (foci indicated by star, zone of all possible swell source foci compatible with spectrogram derived source-to-receiver distance indicated by two white lines). (b-f) Distribution of peak period of swell predicted by NWW3 analysis for 1826 December 2005 during which swell from the source indicated in Figure 6a (denoted I) and swell from a previous storm which followed a similar path (denoted II) propagated south toward the Ross Sea (bottom center of maps). Red colors denote the advancing band of long-period swell (with frequency in the $0.05-0.1 \mathrm{~Hz}$ band observed by the Nascent Iceberg seismometer). Deepest red color $(\sim 16--20 \mathrm{~s}$ period) advances fastest southward across the Pacific, because in the deep water limit, long waves have faster group velocity than short waves. Figures $6 \mathrm{~d}$ and $6 \mathrm{f}$ show projected peak period fronts (dashed white lines) arriving at Nascent. (g) Spectrogram of seismometer signal at Nascent Iceberg showing arrival of swell from the 18 February storm (see Figure 6a). Gray bands denote the times (labels appear on the bands in Figure 6h) associated with the NWW3 analysis pictured in Figures 6b-6f. The onset of swell energy at $\sim 0.04 \mathrm{~Hz}$ at the time of Figure 6f (26 December 2005) agrees with the arrival of peak periods $>16 \mathrm{~s}$ implied by the NWW3 analysis. (h) Peak frequency (solid line) at a point of the NWW3 analysis just north of the Ross Sea indicated by a star in Figure 6b. The peak frequency at this point at times indicated by gray bands labeled $\mathrm{c}$ through $\mathrm{f}$ are in general agreement (i.e., within $0.02 \mathrm{~Hz}$ ) with the frequency of maximum signal strength seen in the spectrogram above.

in radians per second. Assuming an average frequency of $0.057 \mathrm{~Hz}$ and an average induced displacement of $0.004 \mathrm{~cm}$, the typical energy flux determined from the above expression is $0.2 \mathrm{~mW} \mathrm{~m}^{-1}$.

\section{Summary and Conclusion}

[31] Eighty-three storms distributed across the Indian, Pacific and Southern oceans generated sea swell arrival events in the seismometer record at a site near the seaward calving front of the Ross Ice Shelf (Nascent Iceberg). The vertical motions induced by this swell is significant, because amplitude in the $0.025 \mathrm{~Hz}$ to $0.15 \mathrm{~Hz}$ frequency band can reach $\sim 0.3 \mathrm{~cm}$ for some of the largest storms (in the case of our data: a category 5 typhoon in the equatorial Pacific). In comparison, the background of ice shelf motion in this frequency band is in the submillimeter range. The effects of sea swell on the ice shelf and the ocean cavity beneath the ice shelf are yet to be examined. Previous studies suggest, however, that sea swell forcing may be important in generating ice fatigue and fracture leading to iceberg calving and the break-up of ice shelves, but none have yet conclusively proven this to be true. The observations described here thus provide necessary constraints on sea 
swell arrival amplitude and energy flux, the pervasiveness of sea swell arrival events, and the duration of swell excitation needed in future study.

[32] While well known from oceanographic studies conducted in the late 1950s and early 1960s [Munk et al., 1963], a majority of the sea swell arrivals observed on the Ross Ice Shelf come from distant sources located across the Pacific ocean. The implication of this result is that environmental conditions in regions far from Antarctica can have a tangible mechanical influence on the calving margin of the Antarctic Ice Sheet.

[33] Recently, the Wilkins Ice Shelf partially disintegrated [Braun and Humbert, 2009] (see also http://nsidc.org/news/ press/20080325_Wilkins.html). Previous analysis of other catastrophic ice shelf disintegrations, notably that of the Larsen B Ice Shelf by Massom et al. [2006], suggest that both the season and the year of ice shelf disintegration may be controlled by sea ice extent in the ocean surrounding Antarctica. Both the Larsen B and Wilkins disintegration events occurred in the late February, early March time frame, when sea ice is seasonally least extensive [Gloersen et al., 1992]. In the case of the Larsen B Ice Shelf collapse, which occurred in 2002, the extent of sea ice for that particular Austral summer was anomalously low, and this may have eliminated sea ice damping of sea swell propagating into the Weddell Sea from storms in the South Atlantic and South Indian oceans [Massom et al., 2006]. The observations we report here do not directly assess the influence of sea swell on either the Larsen B or Wilkins ice

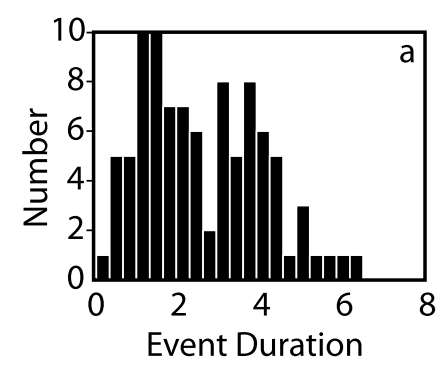

(Days)

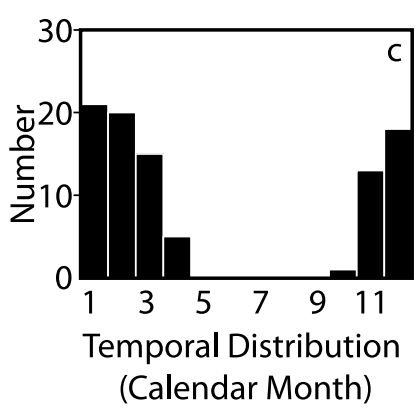

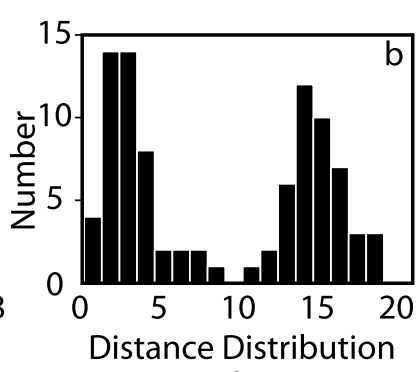

$\left(10^{3} \mathrm{~km}\right)$

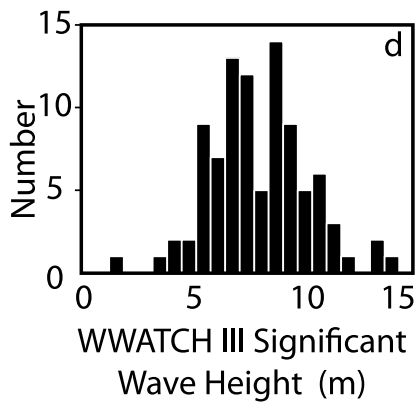

Figure 7. A selection of distributions of event and storm data. (a) Distribution of the time duration of swell arrival associated with each event. (b) Distribution of distances to foci of swell origin (based on equation (1)). (c) Calendar month of observed swell events (note that the seismometer did not operate during the May-September period). (d) Distribution of maximum significant wave height at the foci of swell origin derived from NWW3.

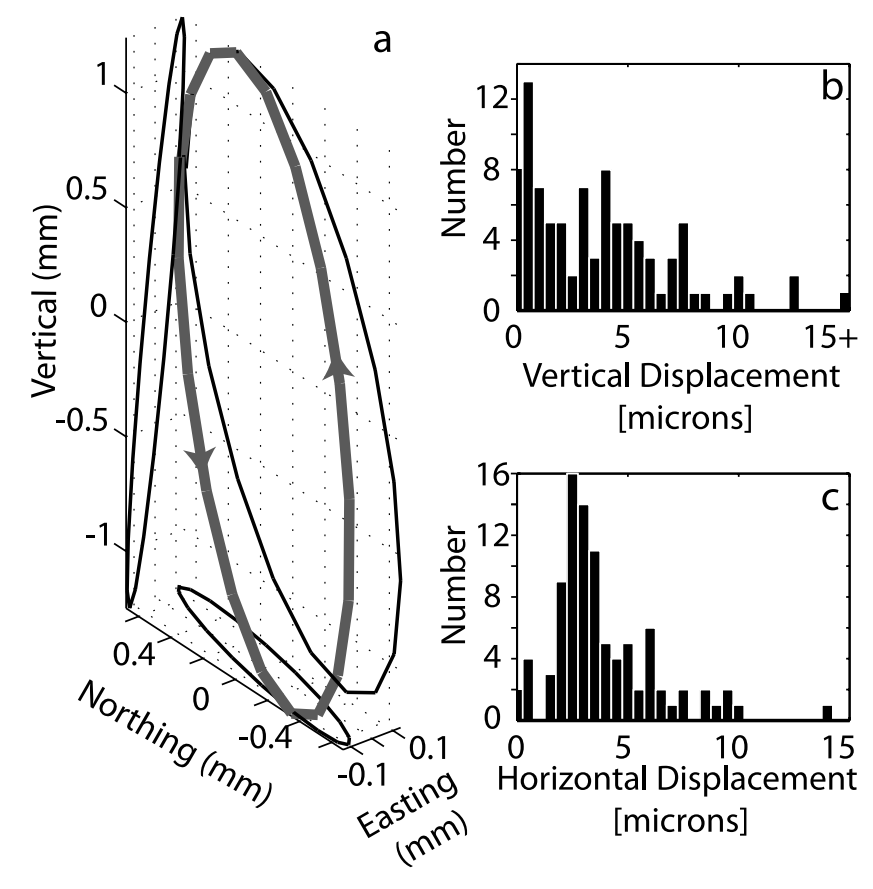

Figure 8. Apparent displacement of the Ross Ice Shelf observed with a seismometer at Nascent Iceberg. (a) Apparent 3-D displacement associated with Typhoon Olaf (category 5, Cook-Austral Islands, 14-19 February 2005). The circular cycle of apparent displacement represents the average of 100 cycles of swell in the frequency range of $0.055 \pm$ $0.002 \mathrm{~Hz}$. Distribution of (b) vertical and (c) horizontal apparent displacements during all observed swell arrival events. In both Figures $8 \mathrm{~b}$ and $8 \mathrm{c}$, the motion was filtered by a Fourier transform method to isolate the $0.042-0.072 \mathrm{~Hz}$ frequency band representative of typical swell arrival events.

shelves during the time of their disintegration, however, our analysis supports the notion that sea swell motions of ice shelves around Antarctica are indeed modulated by sea ice extent. At times of minimal sea ice extent during late February and early March, vertical motions on the Ross Ice Shelf during times of strong storms in the equatorial Pacific can exceed background motion by several orders of magnitude.

[34] Acknowledgments. The authors appreciate insightful suggestions provided by Jeremy Bassis, Rick Aster, and Peter Bromirski. This manuscript was significantly improved by the comments of three reviewers, Rob Massom, Sridhar Anandakrishnan, and particularly helpful comments made by an anonymous referee. Assistance in the field was provided by Jonathan Thom, Kelly Bunt, Olga Sergienko, Katie Leonard, Thomas Wagner, and Marianne Okal. Equipment was provided by the PASSCAL instrument center. Logistical support was provided by the U. S. Antarctic Program of the National Science Foundation. This work was funded by NSF project numbers OPP0229546 and OPP0229492.

\section{References}

Aster, R. C., D. E. McNamara, and P. D. Bromirski (2008), Multidecadal climate-induced variability in microseisms, Seismol. Res. Lett., 79(2), $194-202$.

Bentley, C. R., J. W. Clough, K. C. Jezek, and S. Shabtaie (1979), Icethickness patterns and the dynamics of the Ross Ice Shelf Antarctica, J. Glaciol., 24(90), 287-294.

Braun, M., and A. Humbert (2009), Recent retreat of Wilkins Ice Shelf reveals new insights in ice-shelf break-up mechanisms, Geosci. Remote Sens. Lett., 46(2), 263-267, doi:10.1109/LGRS.2008.2011925. 
Braun, M., A. Humbert, and A. Moll (2008), Changes of Wilkins Ice Shelf over the past 15 years and inferences on its stability, Cryosphere Discuss. $2,341-382$.

Bromirski, P. D., and F. K. Duennebier (2002), The near-coastal microseism spectrum: Spatial and temporal wave climate relationships, J. Geophys. Res., 107(B8), 2166, doi:10.1029/2001JB000265.

Davey, F. J. (2004), Ross Sea bathymetry, Geophys. Map 16, scale 1:2,000,000, Inst. of Geol. and Nucl. Sci., Lower Hutt, New Zealand.

Gilmore, M. H. (1946), Microseisms and storms, Bull. Seismol. Soc. Am., $36,89-119$.

Gloersen, P., W. J. Campbell, D. J. Cavalieri, J. C. Comiso, C. L. Parkinson, and H. J. Zwally (1992), Arctic and Antarctic Sea Ice, 1978-1987: Satellite Passive Microwave Observations and Analysis, 290 pp., NASA, Washington, D. C

Goodman, D., P. Wadhams, and V. Squire (1980), The flexural response of a tabular ice island to ocean swell, Ann. Glaciol., 1, 23-27.

Gutenberg, B. (1912), Die seismische Bodenunruhe, Gerlands Beitr. Geophys., 11, 314-353.

Gutenberg, B. (1947), Microseisms and weather forecasting, J. Meteorol., 2, $21-28$.

Holdsworth, G., and J. Glynn (1978), Iceberg calving from floating glaciers by a vibrating mechanism, Nature, 274(5670), 464-466.

Kristensen, M., V. A. Squire, and S. C. Moore (1982), Tabular icebergs in ocean waves, Nature, 297(5868), 669-671.

Lazzara, M. A., K. C. Jezek, T. A. Scambos, D. R. MacAyeal, and C. J. van der Veen (1999), On the recent calving of icebergs from the Ross Ice Shelf, Polar Geogr., 23(3), 201-212.

Linke, F. (1909), Die brandungsbewegungen des erdbodens und ein versuch ihrer verwendung in derpraktischen meteorologie, Abh. Ges. Wiss Göttingen, 7(3), 58 pp.

MacAyeal, D. R., et al. (2006), Transoceanic wave propagation links iceberg calving margins of Antarctica with storms in tropics and Northern Hemisphere, Geophys. Res. Lett., 33, L17502, doi:10.1029/ 2006GL027235

Macelwane, J. B. (1946), Origin of microseisms, Science, 104, 300-301.

Massom, R. A., S. Stammerjohn, T. Scambos, J. Turner, I. Simmonds, N. Adams, W. Fraser, and M. Pook (2006), Extreme sea ice conditions in the Antarctic peninsular region, their impact and possible links with the disintegration of the Larsen B ice shelf, paper presented at Antarctic Peninsula Climate Variability: Observations, Models, and Plans for IPY Research, Natl. Snow and Ice Data Cent., Boulder, Colo.
Munk, W. H., G. R. Miller, F. E. Snodgrass, and N. F. Barber (1963), Directional recording of swell from distant storms, Philos. Trans. $R$. Soc. London Ser. A, 255(1062), 505-584.

Okal, E. A., and D. R. MacAyeal (2006), Seismic recording on drifting icebergs: Catching seismic waves, tsunamis and storms from Sumatra and elsewhere, Seismol. Res. Lett., 77(6), 659-671.

Oppenheim, A. V., and R. W. Schafer (1989), Discrete-Time Signal Processing, pp. 713-718, Prentice Hall, Englewood Cliffs, N. J.

Press, F., and W. M. Ewing (1948), A theory of microseisms with geological applications, Eos Trans. $A G U, 29,163-174$.

Scambos, T., C. Hulbe, and M. Fahnestock (2003), Climate-induced ice shelf disintegration in the Antarctic Peninsula, in Antarctic Peninsula Climate Variability: Historical and Paleoenvironmental Perspectives, Antarct. Res. Ser., vol. 79, edited by E. Domack et al., pp. 79-92, AGU, Washington, D. C.

Squire, V. A., W. H. Robinson, M. Meylan, and T. G. Haskell (1994), Observations of flexural waves on the Erebus-Ice-Tongue, McMurdoSound, Antarctica, and nearby sea-ice, J. Glaciol., 40(135), 377-385.

Stein, S., and M. Wysession (2003), An Introduction to Seismology, Earthquakes, and Earth Structure, 485 pp., Blackwell, Malden, Mass.

Tolman, H. L. (2002), User manual and system documentation of WAVEWATCH-III version 2.22, Tech. Note 222, 139 pp., NOAA, Washington, D. C

Wadati, K., and K. Masuda (1935), On pulsatoric oscillations of the ground, Geophys. Mag., 9, 299-340.

Wadhams, P., M. Kristensen, and O. Orheim (1983), The response of Antarctic icebergs to ocean waves, J. Geophys. Res., 88(C10), 6053-6065.

Wiechert, E. (1904), Verhandlungen der zweiten Internationalen Seismologischen Konferenz, Strassburg, 1903, Gerlands Beitr. Geophys., 2, 41 43.

Williams, R. T., and E. S. Robinson (1981), Flexural waves in the Ross Ice Shelf, J. Geophys. Res., 86(C7), 6643-6648.

L. M. Cathles IV and D. R. MacAyeal, Department of Geophysical Sciences, University of Chicago, 5734 South Ellis Avenue, Chicago, IL 60637, USA. (mcathles@uchicago.edu; drm7@midway.uchicago.edu)

E. A. Okal, Department of Earth and Planetary Sciences, Northwestern University, Locy Hall, 1850 Campus Drive, Evanston, IL 60208, USA. (emile@earth.northwestern.edu) 